\title{
Consanguineous matings in the Egyptian population
}

\author{
M HAFEZ*, H EL-TAHAN*, M AWADALLA $\dagger$, H EL-KHAYAT $\dagger$, A ABDEL-GAFAR,+ \\ AND M GHONEIM+
}

From *the Genetics Unit, Pediatric Department, Mansoura University; †the Pediatric Department, Ain-Shams University; and $\ddagger$ the Department of Community Medicine, Mansoura University, Egypt.

SUMMARY A total of 26554 Egyptians was ascertained to study the incidence of consanguineous marriages. They were of different ages, different socioeconomic standards, and from differentin areas. There were 7646 from urban areas, 11280 from suburban areas, and 7628 from rural areas. The incidence of consanguineous matings in the general population was found to be $28.96 \%$ withir an average inbreeding coefficient of 0.010 , which could be considered high. The highest incidence was that in the rural areas. First cousin marriages occurred more often than the other types of $\underset{ }{\supset}$ consanguinity.

Two persons are said to be consanguineous if they have at least one ancestor in common and, in practice, this common ancestor is usually taken to be no more remote than a great-great grandparent.

The association between consanguineous marriages and genetic defects has been observed for a long time. The diseases observed in the offspring of these marriages include those resulting from autosomal recessive or multifactorial inheritance.

Consanguinity rates are different in different countries. $^{1-5}$ This difference is usually related to the race, the isolation of the society, and the religion. For this reason we felt that it was important to study the rate of consanguineous matings and estimate the average inbreeding coefficient in the Egyptian population.

\section{Material and methods}

A total of 26554 Egyptians was ascertained in the study. The samples were taken from different areas to reflect properly the incidence of consanguinity. To randomise the sampling, the ascertainment was as follows.

(1) Urban. A total of 7646 was taken from the cities of Cairo and Alexandria. We chose various schools, university faculties, and companies in different districts, and all the people in each were ascertained.

(2) Suburban. A total of 11280 was taken from Mansoura and Talkha. Various primary and secondary schools and companies in different districts were chosen, and all the people in each

Received for publication 21 May 1982. were ascertained. In addition, all persons examined in the outpatient clinics of Pediatrics, $\overrightarrow{\mathrm{c}}$ Ophthalmology, and Surgery in the universityo hospital during the previous 6 months have been: included. However, patients with inheritedo diseases are usually referred to the Genetics Unit, so they were mostly not included.

(3) Rural. A total of 7628 , who were all the familieső in four villages located in different areas and $\mathbb{Q}$ representing the classical Egyptian village, was $\overrightarrow{\hat{O}}$ ascertained.

We recorded the relationship between the two spouses if the subject was married, and of the parents if the subject was a child or an unmarried adult.

For the purposes of classification, the relationshipo was divided into six groups as shown below.

Group A. Marriage between double first cousins.

Group B. Marriage between first cousins.

Group C. Marriage between first cousins once removed.

Group D. Marriage between second cousins.

Group E. Marriage beyond second cousins.

Group F. No relationship.

The incidence of consanguinity was expressed as the average inbreeding coefficient ${ }^{6}=\Sigma$ PiFi.

\section{Results}

The incidence of consanguineous matings in the Egyptian people in general and in the urban,

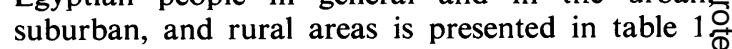
The average consanguinity rate is $28.96 \%$. However it is $22.05 \%, 26.79 \%$, and $39.11 \%$ in the urban 
TABLE 1 The incidence of consanguinity in the Egyptian population.

\begin{tabular}{|c|c|c|c|c|c|c|c|c|c|c|c|c|c|c|}
\hline \multirow[t]{2}{*}{ Area } & \multicolumn{2}{|l|}{ Total } & \multicolumn{2}{|c|}{$\begin{array}{l}\text { Consanguineous } \\
\text { parents }\end{array}$} & \multicolumn{2}{|c|}{$\begin{array}{l}\text { Double first } \\
\text { cousins }\end{array}$} & \multicolumn{2}{|c|}{ First cousins } & \multicolumn{2}{|c|}{$\begin{array}{l}\text { First cousins } \\
\text { once removed }\end{array}$} & \multicolumn{2}{|c|}{ Second cousins } & \multicolumn{2}{|c|}{$\begin{array}{l}\text { Beyond second } \\
\text { cousins }\end{array}$} \\
\hline & No & $\%$ & No & $\%$ & No & $\%$ & No & $\%$ & No & $\%$ & No & $\%$ & No & $\%$ \\
\hline (1) Urban & 7646 & $28 \cdot 77$ & 1686 & $22 \cdot 05$ & 36 & 0.47 & 868 & $11 \cdot 35$ & 223 & $2 \cdot 92$ & 275 & $3 \cdot 60$ & 284 & $3 \cdot 71$ \\
\hline (2) Suburban & 11280 & 4245 & 3022 & $26 \cdot 79$ & 14 & 0.12 & 1482 & $13 \cdot 14$ & 467 & $4 \cdot 14$ & 616 & $5 \cdot 46$ & 443 & 3.93 \\
\hline (3) Rural & 7628 & $28 \cdot 77$ & 2984 & $39 \cdot 11$ & 8 & 0.11 & 1397 & $18 \cdot 31$ & 578 & $7 \cdot 58$ & 544 & $7 \cdot 13$ & 457 & $5 \cdot 99$ \\
\hline Total & 26554 & 99.93 & 7692 & $28 \cdot 96$ & 58 & 0.22 & 3747 & $14 \cdot 10$ & 1268 & $4 \cdot 77$ & 1435 & $5 \cdot 40$ & 1184 & $4 \cdot 46$ \\
\hline$Z_{1}(1 \& 2)$ & & & \multicolumn{2}{|c|}{$7 \cdot 507$} & \multicolumn{2}{|c|}{$4 \cdot 137$} & \multicolumn{2}{|c|}{$3 \cdot 709$} & \multicolumn{2}{|c|}{$4 \cdot 538$} & \multicolumn{2}{|c|}{$6 \cdot 160$} & \multicolumn{2}{|c|}{0.776} \\
\hline$Z_{2}(1 \& 3)$ & & & \multicolumn{2}{|c|}{$23 \cdot 280$} & \multicolumn{2}{|c|}{$4 \cdot 150$} & \multicolumn{2}{|c|}{$12 \cdot 158$} & \multicolumn{2}{|c|}{$12 \cdot 978$} & \multicolumn{2}{|c|}{$9 \cdot 681$} & \multicolumn{2}{|c|}{$6 \cdot 566$} \\
\hline$Z_{3}(2 \& 3)$ & & & \multicolumn{2}{|c|}{$17 \cdot 671$} & \multicolumn{2}{|c|}{$0 \cdot 2$} & \multicolumn{2}{|c|}{$9 \cdot 534$} & \multicolumn{2}{|c|}{$9 \cdot 652$} & \multicolumn{2}{|c|}{$4 \cdot 586$} & \multicolumn{2}{|c|}{$6 \cdot 288$} \\
\hline
\end{tabular}

Sienificance $=$ or $> \pm 1.96$

TABLE 2 Average inbreeding coefficient in the Egyptian population.

\begin{tabular}{|c|c|c|c|c|c|}
\hline & Total number & Double first cousins & First cousins & $\begin{array}{l}\text { First cousins once } \\
\text { removed }\end{array}$ & Second cousins \\
\hline $\begin{array}{l}\text { Number } \\
\text { Proportion (Fi) } \\
\text { Inbreeding (Fi) } \\
\text { PiFi }\end{array}$ & 26574 & $\begin{array}{l}58 \\
0 \cdot 0022 \\
0 \cdot 125 \\
0 \cdot 0003\end{array}$ & $\begin{array}{l}3747 \\
0 \cdot 14100 \\
0 \cdot 0625 \\
0 \cdot 0088\end{array}$ & $\begin{array}{l}1268 \\
0.004775 \\
0.0313 \\
0.00015\end{array}$ & $\begin{array}{l}1435 \\
0.05400 \\
0.0156 \\
0.0008\end{array}$ \\
\hline
\end{tabular}

$\Sigma \mathrm{PiFi}=0.01005$

suburban, and rural areas respectively, with a significant increase in the rural areas, and it is significantly higher in suburban compared to urban areas. The highest incidence in all areas is that of first cousin marriages, which are also significantly higher in the rural area compared to the suburban and urban areas. Furthermore, the incidences of other types of matings are significantly higher in the rural than in the other two areas, except that of double first cousins which is higher in urban areas.

Table 2 presents the average inbreeding coefficient in the Egyptian people in general, which is 0.010 .

\section{Discussion}

The incidence of consanguineous marriages usually differs from area to area depending on the isolation and customs of the society and the religion and laws in such areas. In Egypt, we found the total incidence to be quite high. However, it is significantly higher in rural areas compared to suburban and urban areas. Such results could have been expected since the rural society is somewhat isolated and the family relations are stronger than in urban areas.

Uncle-niece and aunt-nephew unions occur in such places as Israel and the Far East. ${ }^{1-5}$ However, in our country, such unions do not take place since the religion and law do not permit marriages of persons more closely related than first cousins. However, from the genetic point of view, uncleniece and aunt-nephew matings are the same as double first cousin matings $\left(R=\frac{1}{4}\right.$ and $F=\frac{1}{8}$ ) which are allowed in our country. Also, a man who is in law the uncle of his half sister's daughter is genetically the same as a first cousin marriage $\left(R=\frac{1}{8}\right.$ and $\left.F=\frac{1}{16}\right)$.

In our study, the highest incidence is that of first cousin marriages, particularly in the rural areas. However, it has long been known that, in a recessive disorder, the proportion of affected offspring of first cousin unions is higher than that of parents with fewer genes in common. ${ }^{7-9}$

Biological inbreeding, the effect of consanguineous matings, can be quantified by the inbreeding coefficient of a person. The average inbreeding coefficient in the Egyptian population is found to be 0.010 , which is very high compared to most Western societies, where the average inbreeding coefficient is always less than $0 \cdot 001 .^{56}$ However, in some isolated societies it may be greater than $0 \cdot 04,{ }^{2}{ }^{6}$ where it is obviously influenced by marriage customs. Our findings are in agreement with this since we found that the average inbreeding coefficient is highest in the rural areas, then the suburban areas, and lowest in the urban areas.

\section{References}

1 Centerwall WR, Centerwall SA. Consanguinity and congenital anomalies in south India. Indian J Med Res 1966;54:1160-7.

2 Indira K, Sastry VN, Sreeramulu P. Study of the incidence of consanguinity in children. Environ Child Health $1976 ; 10: 214$. 
3 Rao PSS, Inbaraj SG. Inbreeding effects on human reproduction in Tamil Nadu of South India. Ann Hum Genet $1977 ; 41: 87-98$.

4 Costeff H, Cohen BE, Weller L, Rahman D. Consanguinity analysis in Israeli mental retardates. Am J Hum Genet 1977;29:339-49.

5 Roberts DF, Roberts MJ, Poskanzer DC. Genetic analysis of multiple sclerosis in Orkney. $J$ Epidemiol Comm Health 1979;33:229-35.

6 Emery AEH. Methodology in medical genetics. Edinburgh: Churchill Livingstone, 1976:16.
7 Morton NE. Empirical risks in consanguineous marriages: $\stackrel{\mathscr{D}}{\rightarrow}$ birth weight, gestation time, and measurements of infants. Am J Hum Genet 1958;10:344-9.

8 Morton NE. The morbidity of children from consanguineous marriages. Prog Med Genet 1961;1:261.

9 Sinclair S. Familial mental retardation and parental consanguinity. Indian J Med Res $1971 ; 59: 1050-3$.

Requests for reprints to Professor M Hafez, Genetics Unit, Department of Pediatrics, Faculty of Medicine, Mansoura University, Mansoura, Egypt. $\overrightarrow{0}$ 